\title{
The Films of Atom Egoyan
}

\author{
By Ewa Mazierska
}

Fall 2002 Issue of KINEMA

INSTITUTIONS AND INDIVIDUALS IN THE FILMS OF ATOM EGOYAN

The majority of Atom Egoyan's films are set in contemporary Canada, a country regarded as one of the most civilised in the industrialised world, famous for its affluence, good working conditions, relative social equality and excellent standard of social welfare. 'Egoyan's Canada' conforms to this picture, as his characters usually enjoy a comfortable and economically secure existence. In spite of comfort and affluence, they rarely give the impression of being happy. On the contrary, they seem to be unfulfilled, emotionally constrained, as well as suffering other problems associated with the dark side of the 'postmodern condition. (1) The purpose of this article is to discuss their situation as an illustration and critique of this condition.

\section{Institutions in private lives}

One of the features of their lives is domination by institutions, which dictionaries define as 'organisations or establishments, founded for specific purposes'. This phenomenon is not unique either to contemporary Canada, or modern reality in general, neither is Egoyan the first person to recognize this. In fact, the view that contemporary society becomes more and more subordinated to the rules of institutions can be found in many modern social theories, such as those of Karl Marx, Max Weber and Ferdinand Toennies (Giner 1972; Sayer 1991). Those philosophers-sociologists noted the shift from relations of personal dependency to relations which are 'impersonal' and mediated by such 'things' as money and bureaucracy, the move from Gemeinschaft to Gesellschaft. However, when Marx and Weber discussed the growth of rationality in human life, they mainly referred to such institutions as states, laws, parliaments, political parties and economic organisations. Moreover, the domination of human lives by institutions, which those authors predicted, constituted part of what Zygmunt Bauman describes as the 'panoptic system of social integration and control' which was a defining feature of modern society (Bauman 1997:146). In contemporary, postmodern, or 'liquid modern' times, as Bauman and Giddens argue, the metaphor of panopticum does not stand any more, as control was deregulated and privatized. This is revealed, amongst other things, in the 'disembedding of the social system' - the 'lifting out' of social relations from local contexts of interaction and their restructuring across indefinite spans of time-space, and consequently, weakening of such old institutions as parliaments, political parties and even nation states (Bauman 1997, 2000; Giddens 1990). This, however, does not mean (as Bauman seems to suggest in some of his writings) that all institutions became obsolete. Rather the power, attached to the old style, 'grand' institutions, moved to smaller, private establishments, to which people submit voluntarily (or at least it seems as if they relent to them without coercion). I refer particularly to organisations whose aim is to fulfil such personal needs as sexual instincts, child rearing, looking after the elderly, talking and sharing company.

Accordingly, Egoyan does not dwell on how states and parliaments affect people's lives. Instead, he concentrates on the formalisation of the most private spheres of life. The shift from informal to formal and the blurring of the borders between public and private is represented by the very choice of Egoyan's characters they are people paid to perform tasks which used to be regarded as highly personal. This applies, amongst others, to the title role of The Adjuster (1991), Noah Render, whose job consists of assessing the losses caused by fires, floods and other disasters, but also helping his clients to return to normal life. This involves finding a place for them to live (in this respect he resembles his biblical namesake), psychological counselling and even sexual relations with his clients, both male and female. In one scene, showing the extreme formalisation of the private (or 'casualisation' of professional life), Noah makes love to his client and at the same discusses the intricacies of the insurance claim.

Sweet Hereafter (1997) casts as the main character Mitchell Stephens, a lawyer, who specialises in winning damages for the victims of accidents. He offers his services to the families of children, killed in a school bus accident in a small town in British Columbia. Similar to Noah, he perceives his role not only as sorting out the financial side of things for his clients, but also providing them with psychological help. He tries to befriend the parents of the dead children, to convince them that they suffered an injustice and that winning 
compensation will bring them peace of mind. Evidence of his noble intention is his gift of a brand new computer to Nicole, paralysed in the accident.

Egoyan pays the greatest attention to the services which are meant to fulfil sexual or erotic requirements. His films portray prostitutes and their clients (Calendar; 1993), men visiting strip clubs and the naked dancers who work there (Exotica; 1994), men addicted to telephone sex and the women who work on the chat lines (Family Viewing; 1987, Calendar), single mothers and men hired to impregnate them (Exotica), porndirectors, porn-actors and their viewers (Speaking Parts; 1989, The Adjuster), as well as film censors (The Adjuster). It seems as if Egoyan exhausted the cinemas repertoire of all 'erotic jobs'. I would argue that the director's obsession with sex mediated by money, limited by time and 'structured' by strict rules of behaviour, can be explained by the belief that if sex can be institutionalised, then everything can. The impression of the omnipresence of institutionalised, commercialised and commodified sex, as some critics observed, is strengthened by the lack of any other forms of eroticism (Shary 1995:16). There are hardly any romantic stories in Egoyan's films and family relationships, as will be discussed further, usually conform to the same rules as prostitution and pornography. Moreover, those who indulge in formalised sex, are not archetypal deviants, living on the margin of society, but otherwise normal, even decent citizens, representing the urban middle classes: tax inspector (Exotica), photographer (Calendar) or business man (Family Viewing).

Institutionalisation of private lives is also suggested by Egoyan's choice of setting. Places which people visit or are sent to in order to have their private needs fulfilled in a formal way, are common locations for Egoyan's narratives. In Speaking Parts this is a hotel, in Family Viewing - a nursing home, in The Adjuster - a motel, in Exotica - an erotic club. On the other hand, the places which symbolise communal spirit and informality of Gemeinschaft, such as pubs or village shops, are either completely absent from his films or, as in the case of Armenian churches in Calendar, do not fulfil their natural function, but are objects of a distant tourist gaze. Even houses are usually isolated from towns or housing estates and thus their inhabitants are deprived of the chance of having neighbours. Moreover, there is always an aura of formality and temporariness about them. This applies particularly to the Renders in The Adjuster, who live on an unfinished housing estate, in the only inhabited building, which was never a proper house, but a show house, complete with a row of plastic books.

\section{Charity and business}

Egoyan's portrayal of institutions reveals a paradox or contradiction, which is at the heart of the drama, experienced by his characters. Services, even if they deal with people's highly private problems, operate in the capitalist, rational economy. Their ultimate goal is to generate maximum profit for minimum effort, and in order to achieve this, they have to treat each client uniformly. On the other hand, people who use 'private' services, believe that they deserve attention, love and charity purely for who they are and want to be treated as individuals who have unique needs and desires. In other words, when they use institutions which are meant to substitute for their families and local communities, they want to be treated as one's own relatives or friends. This is recognized by the services which try to emulate the aura of charity and informality when behaving in a strictly business-like fashion.

In the case of Noah in The Adjuster, the gap between his charitable appearance and business-like reality manifests itself in his different behaviour at work and at home. At work he assumes the role of protector of his clients. It begins when he arrives at the site of a catastrophe, puts his hand on the arm of his client and says: 'I understand how you feel. You are in a state of shock. I have come to help you'. This role seems to be very successful, as he almost instantly wins the trust of his clients. At a certain stage they find him indispensable, call him their 'guardian angel' and kiss his hand in a gesture of servility and respect. At home, however, Noah abandons the language of help and compassion and admits to his wife that his job consists of judging 'what has value, and what has not'. His, or rather his insurance company's altruistic intentions are put further into doubt by the futility of his efforts - his clients wait for money is prolonged and life in a cheap, shabby motel makes them depressed and vulnerable. At some point the suspicion arises that his language of help and compassion and his highly personal style is only a means to keep his clients quiet and let the insurance company gain time in order to avoid paying high costs. One can risk the statement, that probably the people will be better off without the help of the adjuster - their return to normal life will be less smooth, but they will lose no time passively waiting for help and pondering on what they have lost. The 
same language of help, compassion and understanding is used by the employers of the telephone sex service in Family Viewing and the erotic club in Exotica. In Exotica the apparently personal attitude to clients manifests itself also in the idea of the 'private dance', performed by the naked women at the tables of those who are prepared to pay five dollars. Eric, the disc-jockey, encourages guests to use this opportunity, claiming that five dollars for receiving such a personal service, is really a bargain. Yet, the claim of 'personalisation' of the table dance, is reduced by its cheapness and universality; everybody who can pay, can use it. Its personal character is limited even further by the strict code of behaviour, imposed on the clients.

The manager of the nursing home in Family Viewing does not claim to be a selfless 'angel', but refuses to admit that his activity is simply a way to earn his living. Instead, he claims that there are two sides to his work: charitable and business-like and that he tries to balance these two sides. However, his words are contradicted by scenes from the lives of the old people who use his service; the 'charitable' side is reduced to fulfilling their basic needs. They stay in bed all day, in ugly dormitories, lacking any character and are practically ignored for the whole day. Their only entertainment is watching television, every person has a tv set, constantly switched on, irrespective of their individual wishes. The personnel seem to be too busy or indifferent to talk to the old people or even to remember their names. On the contrary, every person is addressed in the same way, everybody receives the same food, served in an shabby way and every bed stands the same distance from the tv set. The best indication of the anonymity of the individual in this institution is observed when one of the old women dies and her identity is changed without arousing any suspicions.

Although institutions claim that they cater for individuals better than families, the assumed personal bond between them and their clients does not protect the latter from being punished by the former when they break the code of conduct imposed on them. A whole catalogue of such cases appears in Exotica. Thomas, the homosexual owner of a pet shop, who smuggles the eggs of exotic birds into Canada, invites another man to his home, whom he met during a concert. They make love, but in the morning Thomas discovers that the eggs he kept in an incubator, have disappeared and finds a message on his answering machine informing him that the lover was a customs officer who already became suspicious of him at the airport. Similarly, although Francis is referred to as a 'special' guest by the owner of Exotica and has a truly special relationship with Christina, who works in the club which resulted from the fact that he knew her before she started working there, still he must pay like everybody else. Moreover, he is punished, being thrown out of the club and severely beaten up, when he touches Christina while she dances at his table.

These examples show not only the difference in the objectives of institutions and individuals whom they are meant to serve, but also the imbalance in their mutual relationship - institutions are well organised, powerful and ruthless (albeit invisible), individuals are disconnected, weak and vulnerable. Although the former claim that they 'adjust' to the latter, that they are 'consumer-oriented', in reality their clients must put up with what is offered to them. The power of institutions manifests itself in the capability of people who work for them, such as insurance men, lawyers and sex workers, to influence the lives of others. Yet, these insurance men, lawyers and sex workers can't be equated with their institutions, as they only 'mediate' between the rules of omnipresent capitalism and individuals exposed to the system of bureaucracy. I will risk the statement (which I will try to demonstrate later) that they are more miserable victims of capitalistic exploitation than their clients, as they who are served only risk losing their money, while those who serve them pay the price of their own integrity.

\section{Families and institutions}

Egoyan's institutions, as was already mentioned, try to emulate the family atmosphere of informality, friendliness and emotional intimacy. The best example is erotic club Exotica, where exotic plants and dim lights, protecting clients' privacy, soothing music and warmth are all meant to help them to feel more relaxed and open than at home. Moreover, those who work there, play various family roles for each other Zoe, the owner of the club, is like a mother to Christina, and Eric, who used to be Christina's lover, behaves like her father and is the biological father of the child, Zoe is carrying. Families, on the other hand, never have a family atmosphere; they are typically places of emotional tension, misunderstanding and loneliness. There is virtually nothing like a 'proper family' in any of Egoyan's films, as all families are dysfunctional, pathological or broken. For example, Peter in Next of Kin (1984) left his birth family and entered another by pretending to be their lost son and brother, Bedros. Francis in Exotica and the photographer in Calendar 
were betrayed by their wives and lost their children. The daughter of Francis was murdered by an unknown killer, the photographer's daughter does not live either with his father or with her mother and she is only his foster child. Mitchell is divorced from his wife, and his daughter, drug-addicted Zoe, accuses him of indifference and contacts him only when she needs money. Even the images of archetypal suburban, happy houses can be deceptive, as they can hide lives filled with suffering. Hence, Christina in Exotica who lives in such a house confesses to Francis whose daughter she babysits how unhappy she feels.

The proliferation and accessibility of 'private' services can result from family decline and be its cause. This is shown in Exotica and Calendar - Francis and the photographer started using paid services, providing them with company and sex, only after they lost their wives. Similar to these two men, Mitchell seeks a surrogate family after he lost his own. Yet, in contrast to Francis and the photographer, who turned to 'external' services in order to have their intimate needs fulfilled, he uses his own position as a 'service-provider' to find a surrogate family which is a community of people who lost their children in the bus crash. His offer to help them fight for compensation from the bus company, can be interpreted as a symbolic seeking for an excuse for his own failures as a family man by putting the blame on 'others'. Another sign of his desire to somehow substitute his own family for a new one is his special attitude to teenage Nicole, the only child, who survived the accident. As was already mentioned, he presents her with a computer and spends more time with her than with other members of the grieving community. This might by explained by the crucial role Nicole is expected to play in his lawsuit, but might also have something to do with her lameness - being paralysed and completely dependent on her parents, she is as helpless as his own 'lame child', Zoe.

In Family Viewing, the relation between the decline of the family and the use of erotic services can't be reduced to a simple 'cause-effect' pattern as the breakdown of Stan's family was a complex, multi-dimensional process. Firstly, it is suggested, that having the inclination to sado-voyeuristic games, he never had a normal family and never wanted one. What he wished for was to have somebody able to fulfil his strange needs in exchange for economic security. His first wife, who could not cope with being treated this way, left him and soon he installed at home a new, bimbo woman called Sandra, able to meet his sexual requirements. Stan does not make any secret of the fact that his attitude to his new wife (or lover) is purely instrumental. Asked by his son if he loves Sandra, he bursts out laughing and answers: 'I like her simplicity'. Stan's treatment of both his partners suggests that he hardly differentiates between a wife and a prostitute. For him the rules of paid, regulated and commodified sex is a norm of family life; he does not offer love, but he also does not expect affection or tenderness. His second partner seems to understand his business-like attitude perfectly and is reconciled with her role as a sex provider, trying to perform it in an 'economical way', sparing effort and time. Her erotic repertoire is limited to several mechanical gestures, performed with the accompaniment of video equipment and a telephone sex voice. Moreover, when her husband is away, she tries to seduce Van, her teenage step-son.

A similar attitude to sex and family life manifests itself in the behaviour of Mimi and Bubba in The Adjuster, a couple who asks the Renders to allow them to use their house as a film location. Mimi and Bubba think about their relationship purely in the categories of performance. They perform elaborate sex spectacles for each other and for other people's enjoyment, often using modern media, strange settings and other 'performers' as facilitators of their erotic bond. This, of course, excludes intimacy from their mutual relationship. The public character of their connection is shown best in a scene when Mimi dances in an empty stadium, watched by the entire football team and her own husband. Moreover, Bubba's gaze straight into the camera suggests that he is also aware of the presence of another audience - the audience of Egoyan's film. Francis, Mitchell and the photographer lost their families, but it is suggested that they preserved the memory or an idea of a normal family. Stan, Mimi and Bubba, on the other hand, seem to be an ideal product of institutionalised society, as they neither have normal families, nor want them, nor know how they should function. Relations which are mediated by 'things' (money, modern technology) and governed by rules, are the only ones which they are able to appreciate and enjoy. Another example of the blurred border between family and institution, private and public, is shown in The Adjuster. Not only does Noah's professional life involve sharing informalities and intimacies with his families, but the genesis of his own family is 'institutional'. In the last scene of the film where his home is destroyed by fire, we learn that Hera was once Noah's client - he met her when her house was burnt down. Thus, the Noah's family become a direct extension of the institution.

Egoyan often shows relationships which are incestuous or paedophilic. Characteristically, they are treated 
as acceptable, domesticated, even normal by those involved in them. I refer to Nicole and her father in Sweet Hereafter who are shown making love as true, romantic lovers, in a barn, lit by candles. Later, when Nicole is paralysed as a result of the accident, her father decorates her room with toys and get well cards and carries her, as if she was a little girl. This act bears a multitude of connotations. It can be interpreted as a sign of the father's altruistic love and unconditional commitment to his daughter, but also, by exploring the vulnerability, helplessness and childishness of Nicole, emphasizes the immorality of his earlier behaviour.

Paedophilic and incestuous undertones appear also in the relationship between Francis and Christina, when she performs a striptease in school uniform, then dances at Francis's table. However, there is much more to it than 'ordinary' perversity as, Christina who used to babysit for Francis' daughter, epitomises love and innocence, which was lost with the loss of his family. It can be argued that Christina 'plays' his daughter, who will never reach school age, his wife, who will never be his lover again and even herself from the time, when she was a teenager and visited his home. According to Egoyan's own words, Francis 'is projecting onto her something that's extremely pure'. Still, 'the environment of the club is sexual, so that can't help but imbue what he's seeing in her with a sexual content. And that tortures him, as he's trying to work out some sort of therapeutic relationship with her. He's trying to heal some sense of grief - which becomes infused with guilt, because of where he's chosen to conduct this therapy'(Romney 1995:7-8).

In other words, Francis's efforts to recreate the innocence of his past is doomed to failure, because he uses methods which are by their very nature exploitative. Christina seems to genuinely enjoy the strange relationship with Francis. She treats him with tenderness and compassion and admits that she regards their relationship as precious. Yet, this can be regarded as less a testimony of the purity of their bond than a measure of her disappointment in more 'standard' relationships with her parents and her boyfriend and an indication of her innocence and naivety, which is an object of male exploitation. There is a profound analogy between institutionalised and deviant sex in Egoyan's films, as the main principles of both activities are reduction and substitution - one side is reduced by the other to sexual objects, which can be replaced by other objects. This analogy between two kinds of sex is most profound in Speaking Parts whose protagonist, Clara, being in love with her dead brother, decides to make a TV movie about him and subsequently has an affair with a man called Lance, who plays the main part in her film.

One can also discover that while in Egoyan's first film, Next of Kin, as observed by Timothy Shary, the result of replacing one's true family with a new, 'artificial' one, can on the whole, be positive for everyone involved in such a substitution (Shary 1995:18-19), while in Egoyan's later films such experiments typically end in disaster. This change can be regarded as testimony to the shift in Egoyan's attitude to the society in which, as Bauman describes it, any life-decisions, even those involving one's families and friends, are treated as exercising consumer choice (Bauman 2000:89). I will suggest that in Next of Kin Egoyan draws attention to the potential of the 'consumer attitude' to family and sexual life as a vehicle for achieving emancipation and happiness. In his later works, by contrast, he doubts if such an attitude could bring any advantages, and instead notices many of its despicable by-products.

\section{Media as institutions}

Egoyan's characters rely heavily on modern information and communication technology: cameras, video recorders, televisions, telephones, answering machines, computers etc. Many of them, such as Stan, Hera and the photographer, simply earn their living by working in the media. Moreover, in accordance with the previously mentioned rule of constant intertwining of the private and the public, they use media equipment to fulfil their private obsessions. For example, Stan who is the owner of the company selling video equipment (one of the first of its type in Canada), records every day of the life of his family on videotape. Hera, who works as a censor, secretly videotapes forbidden films for her sister to watch at home. The photographer not only photographs the churches of Armenia, which are later used for the calendar, but also makes a video about his and his wife's trip to this region.

There are many similarities and connections between institutions and media. Firstly, media and modern technology in general, as institutions, mediate between people, replacing direct with indirect communication and mutual with one-way contact. They make communication more accessible and universal, but at the price of making it more superficial and standardized, less informative and personal. The image of somebody unsuccessfully trying to communicate with somebody else by telephone appears in Egoyan's films with 
obsessive regularity. Sometimes this is caused by technical failure - dysfunction of the mediator of the contact. More often, however, it results from the human 'fallacy'; character's inability or unwillingness to convey and respond to messages, mediated and transformed by technology.

This applies to Hera, who woken at night by Noah, phoning her from his car, puts down the receiver and carries on sleeping, the photographer who refuses to reply to messages left on the answering machine by his wife and to Mitchell who continuously rejects his daughter's request for help and understanding. In all cases, those who refuse to talk by phone, do it not because they are indifferent towards those who want to communicate with them, but because their expectations from communication are too high to be fulfilled by contact mediated by technology. Mitchell particularly misses direct, physical contact with Zoe. The symbol of his yearning for his daughter is his recurrent memory of an episode from Zoe's childhood where he rushed her to hospital after she was bitten by spiders. He saved her then because he was physically close to her and perhaps he will be able to 'save her' again if he is able to reach her as a whole person. Yet, every telephone call which finishes with Zoe's attack of hysteria and Mitchell's frustration resulting from his daughter behaviour makes this chance more remote. In this case minimalism of mediated contact is a source of its further diminishing.

Another connection between institutions and media, examined by Egoyan, lies in the fact that media help institutions to proliferate, to widen their access to potential clients and vice versa. They also function as new types of institutions, able to replace 'old' ones. For example, telephone and video can help prostitutes reach more clients (and clients reach more prostitutes), but also telephone sex and pornography can be a substitute of 'classical' prostitution. One can predict that if Egoyan will be faithful to his present interests, his future films will be about cyber-sex.

Amongst all media, most often portrayed by Egoyan are film and video. ${ }^{(2)}$ He seems to share Christian Metz's opinion, expressed in his famous article, 'Notes on two kinds of voyeurism', that cinema (and by the same token video), in contrast to theatre, is particularly suitable to modern audiences. Theatre, writes Metz, is 'a ceremony which is always partly civic, involving more than the private individual: a festival. (...) The theatre still retains (...) something of its Greek origins, of its initial atmosphere of citizenship, of public holidays, when a whole population put itself on display for its own enjoyment. (...) The cinema was born much later than the theatre, in a period when social life was deeply marked by the notion of the individual (...), when there were no longer any slaves to enable "free men" to form a relatively homogenous group, sharing in the experience of a few major affects and so sparing themselves the problem of "communication", which presupposes a torn and fragmented community' (Metz 1985:546-547). This claim is true of Egoyan's characters, such as Lisa, Clara, Stan, the photographer and Francis who by watching films, rather than going to the theatre or opera, exclude themselves from any traditional social life. Watching films is in their case self-perpetuating - the more they watch, the less chance they have to meet somebody personally. Similarly, the more lonely they are, the more time they spend in front of the TV. In contrast, the only one of Egoyan's protagonist, who frequents opera, Thomas in Exotica ends up with a 'proper' lover.

The addictive, perpetuating character of screen images, results, according to Metz, from the exhibitionist and secretive nature of cinema. Watching films means being present to the world which is absent, as 'during the screening of the film, the audience is present, and aware of the actor, but the actor is absent, and unaware of the audience; and during the shooting, when the actor was present, it was the audience which was absent' (Metz 1985:547). The gap between presence and absence renews the viewer's desire to watch, thus guaranteeing the proliferation of cinema as an institution. Egoyan's characters indulge in two kinds of films: pornography (Family Viewing, Speaking Parts) and home movies (Family Viewing, Speaking Parts, Calendar and Felicia's Journey, 1999). The border between them (as between all other institutional and informal activities portrayed by Egoyan) is blurred, as home videos often include pornographic material and pornography is usually home made and of low quality.

If Metz's theory, that watching a film reinforces or reaffirms the absence of what is on screen, is accurate, then Francis' watching the video of his daughter, the photographer's watching the video of his wife, Van's watching the video of his mother, Noah's clients watching the photographs of their old houses, Hera's watching 'dirty' films is a masochistic activity - every time they switch on the video recorder, they remind themselves that they lost their beloved and their own past or that they have no erotic life. At the same time, watching has a 
therapeutic effect on them, as it is the only way to recreate the past, to construct the illusion of its constant existence, to have a sort of erotic life. They are trapped between the confirmation of absence and the illusion of presence. Egoyan himself claims that 'one of the transformations affecting our society is that we always live with the images of the deceased, and for that very reason lack the space to mourn their absence' (Ciment and Rouyer 1994, quoted in Coates 1997:29).

The alienating and constraining, but also therapeutic and therefore addictive character of film images and her own condition as a voyeur is most strongly felt by Hera. She is outraged by her boss's suggestion, that she enjoys pornography and his claim that 'there is nothing wrong or abnormal' in it. Similarly, she detests an erotic show arranged for her in a bus by Mimi and Bubba. Yet, at the same time she can't stop watching 'dirty' films (she even watches the censored films again at home, with her own sister) and 'dirty', perverted people. This can be explained by her own erotic unfulfillment; there is no physical contact between her and Noah, who himself perceives sex mainly as an extension of service towards his clients. The measure of Hera's frustration as a 'sexual being' is her pleasure, derived from contact with a chiropodist, met in a bus. Although this contact is only professional: she visits him regarding her warts, very limited in the most literal sense - he touches her feet with his hands and even painful - he freezes the warts, still, this is the most intimate and pleasant experience she enjoys in the whole film.

Film and video images are able to distort and diminish physical reality - to make the real world so irrelevant to the characters as to be almost superfluous. In Egoyan's world, as Jean Baudrillard put it, 'our own body and the whole surrounding universe become a control screen' (Baudrillard 1985:127). For example, for Clara, Lisa and Stan, as well as for Hilditch in Felicia's Journey video recordings are all that matters for them. They practically gave up all forms of communication with the outside world other than through the electronic media and they need the outside world only as a tool for a continuous supply of images. Moreover, the visual style of Family Viewing, the flatness of the images presenting Stan's family life, recollecting cheap sitcoms, suggests that Stan's very perception of the real world is identical with his perception of videos. Similarly, Clara and Lisa can't tell the difference between the men who they love, characters they play in films and their images on the video screen. The media's power to manipulate reality is also shown in the scene of a 'false funeral', included in Family Viewing. Although the person who was buried was not the one who was meant to be buried, the reaction of the person watching the video is as emotional or even more so than of those who attended the 'proper' funeral. One can say that the world, as Egoyan represents it, is populated and dominated by autonomous signifiers, liberated from the 'tyranny of the signified': instead, tyrannising the real, material world, which they were meant to mirror. The 'chisel-like' quality of media in shaping human lives manifests itself also in characters conformity to certain images, promoted by television programmes and advertising. As Jonathan Romney noticed, Noah plays the friendly insurance man from a TV advert' (Romney 1992:38). However, as the media images change every day, so the people who imitate them are forced to change accordingly. The consequence of this for Noah, who never knows if he is up to his job as he does not know what 'being up' at the moment means, is his constant restlessness and anxiety.

In the reality, which Egoyan represents, it is as difficult to abandon media and new technologies, as it is to give up institutions. Even those, who made a conscious decision to start their lives over again from the very beginning, giving up the falsity of media and institutions, end up using them. This is shown in Family Viewing, when the hero named Van takes his grandmother from the nursing home, where she was continuously exposed to television, to the flat where he lives with his girlfriend. However, in the flat the television is also switched on, only this time the content of the programme is different, consisting of home movies, made by Van's father, Stan. They provide proof that Stan abused his family, including his wife and mother in law. We can believe, that Van's purpose in showing them to his grandmother is cathartic and therapeutic. Yet, the grandmother watches the tapes as passively as she watched television in the nursing home.

It could be argued that there is a parallel between the young protagonist of Family Viewing and Egoyan himself: both condemn the media, but at the same time use them in their criticism. As Linda Hutcheon observes, such an attitude, which she describes as 'complicitous critique', is a typical, even crucial element of postmodern thought: social critics, who belong to this paradigm, cannot escape the very cultural practices they condemn in others, because there is no outside point, from which to judge ( Hutcheon 1989). Yet, Hutcheon argues that complicitous critique is, on the whole, constructive and valuable. I will attach the 
same opinion to Egoyan's critique of the media.

\section{Fragmented identities}

A typical character in Egoyan's film, as was already mentioned, performs conflicting roles. For example, Noah's role as a friendly insurance man, consoler of fire victims, is hardly compatible with that of a good husband and the loyal employee who tries to minimise the losses of his insurance company. Similarly, his role as a friend to one of his clients is incompatible with the role of lover of this client's wife. However, Noah wants to be a good, honest man and satisfy everybody: his wife, his clients, his employer, perhaps even the society or mankind as a whole. The difficulty of his situation is revealed in his talk with a couple of clients when he admits his frustration at being 'stuck in the middle' (between the insurance firm and his clients) and being forced 'to clean the mess', caused by those who sell bogus or tricky policies to naive people. Paradoxically, they are his own clients, who try to comfort him by saying that he is only an adjuster, performing a job, not somebody who 'carries the weight of the world on his shoulders'.

I would argue, that rather than admitting to himself that in certain situations he is forced to lie or that certain roles matter to him more than others, Noah resolves the conflict between the parts he plays by assuming each time a different identity, according to who he deals with at the time or what task he performs. To put it metaphorically, Noah does not respond to given circumstances, according to who he generally is, what he thinks, what are his values, he simply (as his surname suggests) 'renders' the situation. This constant rendering, reciprocating, responding, instead of acting in accordance with himself, leads to fragmentation of Noah's identity, by which I mean a state when a person ceases to have a coherent set of opinions, values, even experiences and memories. At this stage he can't even 'honestly' lie because he has no standard of truth to compare his words or deeds with. Similarly, he can't be alienated because he has no 'true self' to be alienated from: he is only a sum or a function of other peoples lives.

It is worth noticing, that 'fragmented identity' is in fact a contradiction, as according to the dictionary definition, 'identity' implies 'the state of having unique identifying characteristics held by no other person or thing' or 'the state of being the same in nature, quality etc'. As a result, Noah can be perceived as a person without an identity, as 'everybody' or 'nobody'. Such a fragmentation of identity, or even (if we assume that human identity must possess an unifying element, a centre) the disappearance of identity, as Stuart Hall and many other authors argue, is a feature of late modern society (Hall 1992:274-291).

Assuming a new personality in each new situation is not only a device to reconcile the private with the public or different aspects of the public life, but also a method of coming to terms with one's personal loss or confusion. In this case, as was already mentioned, the mechanism of changing identity relies on substituting one's own experiences with similar experiences, but belonging to somebody else. Amongst the victims of the 'faulty mourning', as Egoyan himself describes this phenomenon (Romney 1995:8) are Mitchell who after losing his daughter grieves over other parents lost children, the already discussed Noah who being unable to protect his household and to measure the value of his own life, looks after other people's properties and evaluates others people lives, Clara who after losing her brother makes a film about him and has an affair with an actor, playing her brother and Francis who employs two young women, Christina and his niece to play various roles for him.

The question arises: does 'faulty mourning' fulfil its therapeutic role? The answer is, however, not simple, as according to Egoyan's own words, there are two sides to this 'substitutional grief'. On one hand, this ritual of faulty mourning 'accentuates and exaggerates the sense of loss' which his characters are dealing with, on the other, 'in the process of grieving another person's loss (...) they're somehow underlining and distorting what it is that they've lost in the first place' (Romney 1995:8). In other words, 'faulty mourning' helps them to overcome their trauma, but at the price of immortalising it, or rather its imaginary equivalent. A necessary pre-condition for 'faulty mourning' is not treating other people like full human beings, but - to use Paul Coates' phrase - like a 'blank screen for [their own] projections'. Coates uses this term in reference to Christina who for various men in Exotica is not really an individual, but 'a Platonic Schoolgirl per se' (Coates 1997:22).

Needless to say, such a role, which is also performed by Lance in Speaking Parts and by the women hired through a dating agency by the photographer in Calendar, is degrading. I will suggest that the discomfort, which accompanies viewing Egoyan's films, noted by many reviewers, has something to do with the fact that 
the viewers also tend to treat the film characters as 'blank screens for their own projections' and Egoyan brings that realisation.

Institutions, such as loss adjusting or telephone sex and media images play a crucial role in the therapy by substitution: they provide Egoyan's characters with a form or surface of lost experiences, which they strive to recreate, but never with whole experiences. They always promise more than they are able or want to deliver, thus sustaining the hunger of those who turn to them and guaranteeing their proliferation. Similarly, by entrusting their lives to institutions and media, they become their passive consumers, Egoyan's characters shut themselves in a perpetual present, in a world frozen by images and strict rules of behaviour. This is demonstrated in the repetition, almost ritual of Francis's visits to Exotica, photographers inviting the call-girls, Clara and Lisa watching videos of their beloved Lance, Hilditch watching video tapes of the 1950s cookery television show, hosted by his mother, Gala who was a celebrity chef. In the later case the character's love and attachment to the world frozen on video tapes manifests itself also in the mise-en-scene of his museum-like house, full of mementoes and objects from the 1950s and his 1950s car.

\section{West and East}

A factor, which can't be omitted when discussing the situation of Egoyan's characters, is ethnicity. The director, who himself was born into a family of Armenian immigrants, often juxtaposes his real Canadian characters with Armenians. The most characteristic, from the point of view of ethnicity in defining identity is Calendar, a film in which three different types of Armenians are represented. The photographer, played by Egoyan's himself, is like the film's director, completely assimilated into Western cultures. The photographer's wife, played by Egoyan's wife, can speak both English and Armenian. Their Armenian guide whom they employ on their trip to Armenia, is a 'true' Armenian who can't speak any English. The way the narrative is constructed, emphasizes the cultural differences between the photographer and the guide. The identity of the former is defined solely by media and technology. He seems to have no daughter, only her photograph, no wife, only a video of her and her voice, recorded on the answering machine, no religion, only a calendar with pictures of Armenian churches. In other words, in order to describe himself and his place in the world, he must turn to representations. The guide, on the other hand, does not need any devices to express who he is. His identity is constructed by his Armenian tongue, which can be spoken almost exclusively by Armenians (in contrast, the English language hardly defines the photographer, as English is an international tongue), his history, culture and landscape which he knows and understands in all their subtleties and his relations to his friends and family. Consequently, the guide's identity is more genuine, more robust, stable and self-sufficient than those of the photographer. ${ }^{(3)}$ No wonder, that the photographer's wife, who at the beginning of the story is 'stuck in the middle' between the guide and her husband, and respectively, Armenian and Canadian culture, chooses the former.

There is a profound similarity between the situation of the photographer's wife in Calendar and of Hera in The Adjuster. Both (played by the same actress, director's wife, Arsinee Khanjian) can speak both languages, Armenian and English and seem to belong to both cultures, Armenian and Canadian. This is manifested by her family ties: she lives with Noah who is a 'true' Canadian and her sister Seta, who as a new emigree, can't speak any English and has literally no contact with another Canadians than her brother in law. The close relationship between Hera and her sister increases the emotional barriers between Hera and Noah, similar to the photographer's wife's intimacy with the guide which caused tensions in her marriage. When Hera chats and laughs with Seta in Armenian, Noah, who can't speak their language, practices arching alone. Later on, Hera leaves Noah in the motel where he deals with his clients and goes away with Seta and her son, Simon. It is suggested that she left Noah for good. This act can be interpreted as Hera's choosing true, blood family over a 'post-professional' relationship with Noah and choosing genuine, Armenian culture over Western culture which she finds constraining and false.

Before Felicia's Journey Egoyan exalted the traditions and values, associated with Eastern culture at the expense of Western civilization. This film, on the other hand, brings a somewhat different image of the 'East'. To be sure, the film does not represent any truly Eastern country or region, but only rural Ireland (which in fact is even placed west of Britain), but there are profound similarities in Egoyan's portrayal of this place and Armenia. Both places are green, hilly and agricultural, relatively poor and populated by people whose ancestors also lived there. Both are also literally and metaphorically remote from the cultural centres, and their inhabitants are attached to their traditional ways of life. From such a place the eponymous Felicia, a 
young girl, impregnated by an English boy, begins her literal and metaphorical journey to 'civilization', the last stage of which is London.

In Felicia's Journey, Ireland, unlike Armenia in Calendar, is not a paradise, where one can find freedom and happiness, but an intolerant, xenophobic and suffocating environment, where people have to conform to the strict rules of the local community or are forced to leave. Jonathan Romney, who wrote a review of Felicia's Journey for Sight and Sound entitled it poignantly 'This green, unpleasant land' ( Romney 1999:34-35). At the same time, the film brings the usual Egoyan's criticism of Western (in this case English) civilization, showing Hilditch's pathological dependance on media and some dysfunctional institutions, such as an evangelical hospice. Yet, in spite of the negative portrayal of both cultures, on the one hand traditional and rural, on the other modern and industrial as dangerous and destructive for the individual, the film conveys an optimism, rarely found in Egoyan's earlier films. The optimism results from the fact that Felicia, who at the beginning of the film seemed to be a naive, passive and lacking in confidence young woman: an ideal victim for predators and nutters, in the end finds peace of mind and happiness, working in a municipal garden in London. In contrast to Egoyan's earlier protagonists, Felicia fits neither well Western nor Eastern culture; she is an independent and strong individual. However, it could be suggested, that in order to achieve such a state, one must first travel through various countries and get to know many cultures and people.

\section{Notes}

1. In this article I will not use any rigid definition of the 'postmodern condition', but explicitly or implicitly will refer to ideas formulated by such philosophers and sociologists, as amongst others, Fredric Jameson, Jean-Francois Lyotard, David Harvey, Zygmunt Bauman and Anthony Giddens.

2. The use of film and video by Egoyan attracted the greatest attention from film critics. See, for example, Taubin 1989; Desbarats et al 1993; Shary 1996.

3. The idea that the global expansion of Western culture leads to the erasure of a distinctive Western identity can be found in the works of Anthony Giddens and Zygmunt Bauman. See Giddens 1990; Bauman 1995.

\section{References}

Baudrillard, Jean (1985). 'The Ecstasy of Communication' in Hal Foster (ed.), Postmodern Culture (London: Pluto Press).

Bauman, Zygmunt (1995). Life in Fragments (Oxford: Blackwell).

Bauman, Zygmunt (1997). Postmodernity and its Discontents (Cambridge: Polity Press).

Coates, Paul (1997). 'Protecting the Exotic: Atom Egoyan and Fantasy', Canadian Journal of Film Studies, vol. 6, No. 2, Fall, pp. 21-33.

Desbarats, Carole et al (1993). Egoyan (Paris: Editions Dis Voir).

Giddens, Anthony (1990). The Consequences of Modernity (Cambridge: Polity Press).

Giner, Salvador, (1972). Sociology (London: Martin Robertson).

Hall, Stuart (1992). 'The Question of Cultural Identity' in Stuart Hall, David Held and Tony McGrew (eds.), Modernity and its Futures (Cambridge: Polity Press).

Hutcheon, Linda (1989). The Politics of Postmodernism (London: Routledge).

Metz, Christian (1985). 'Story/Discourse: Notes on two kinds of Voyeurism' in Bill Nichols (ed.), Movies and Methods (University of California Press).

Romney, Jonathan (1992). 'The Adjuster', Sight and Sound, No. 6, p. 38.

Romney, Jonathan (1995). 'Exploitations', Sight and Sound, No. 5, pp. 7-8. 
Romney, Jonathan (1999). 'This green, unpleasant land', Sight and Sound, No. 10, pp. 34-35.

Sayer, Derek (1991). Capitalism and Modernity (London: Routledge).

Shary, Timothy (1995). 'Video as Accessible Artifact and Artificial Access: The Early Films of Atom Egoyan', Film Criticism, vol. XIX, No. 3, Spring, p. 16.

Taubin, Amy (1989) 'Up and Atom', Film Comment, November / December, pp. 27-29.

\section{Author Information}

Ewa MAZIERSKA is Professor of Contemporary Cinema at the Department of Humanities, University of Central Lancashire. Her publications include Masculinity in Polish, Czech and Slovak Cinema, Roman Polanski: The Cinema of a Cultural Traveller, Women in Polish Books (with Elżbieta Ostrowska), Crossing New Europe: The European Road Movie (with Laura Rascaroli), Dreams and Diaries: The Cinema of Nanni Moretti, and From Moscow to Madrid: Postmodern Cities, European Cinema. She also co-edited Relocating Britishness. 